\title{
Investigation of Incidental Learning in a Mathematical Activity on Secondary School Students by Their Success ${ }^{1}$
}

\author{
Abdullah TERECİ, Ministry of Education, Turkey, trcbdllh@gmail.com \\ *Nazan SEZEN-YÜKSEL, Hacettepe University, Turkey, nsezen@hacettepe.edu.tr
}

\begin{abstract}
The aim of this study is to determine the incidental learning level of students by their academic success. The study group consists of 90 students at the $7^{\text {th }}$ grade of a public school. Two tests with central and incidental tasks were used as the data collection tools, consecutively. In order to analyzes the data, descriptive statistics, ANOVA, Mann Whitney U, Kruskal Wallis H and Wilcoxon Signed Ranks tests were used. Considering the study findings, it was seen that the students, who were successful at the achievement tests with central tasks, scored low on incidental tasks while the students who were not successful at the central tasks and whose success at mathematics was considered to be low, got high scores from the incidental tasks. It was observed as a result of the study that the students with low success focused on the distracting information given in the question while the successful students did not focus on the distracting information in the question but concentrated on solving the question during the activity. This study reveals that the students, who are considered to be unsuccessful at mathematics, can be successful if the distracting factors are controlled as they also learn during the activity.
\end{abstract}

Keywords: Selective attention, incidental learning, mathematics education, central task, incidental task Received: 16.12.2020 Accepted: 02.01.2021 $\quad$ Published: 01.02.2021

\section{INTRODUCTION}

In the scope of the education activities, the individuals are expected to gain intentional / desired behaviors that are foreseen by the system through activities. In addition to these, there are also other learnings performed students which are not intentional but occur even if not targeted. As also known, learning is realized formally or informally. While formal learning is generally known as classroom-based and well-structured activities supported with educational activities, informal learning is generally defined as the learning which is not classroom-based nor well-structured. In the informal type of learning, learning can occur out of the scope of teaching activities because the learning is controlled by the learner, himself / herself (Marsick \& Watkins, 2015). Incidental learning, which is a component of informal learning, is the coincidental - accidental learning where the individual learns without concentrating on a particular area (Craik \& Lockhart, 1972). In other words, incidental learning is the process where the individual focuses on one feature of the stimulus but learns another feature of the same (Ahmed, 2017).

Attention is defined as revealing the necessary information sufficiently and when necessary, preventing the acquirement of unnecessary information during the process of learning in humans. The information reinforced by revealing makes the individuals gain the ability to choose during the information processes they will encounter in the future while allowing us to put some information aside due to the prevented information acquirement (Smith \& Kosslyn, 2017). In the scope of the prevented information acquirement, mentioned in this sentence, the unnecessary information to be put aside may be unintentionally stored together with other information to be acquired. This information that is stored unintentionally appears as incidental learning. Incidental learning increases with the complex thinking strategies developed by students, and this situation does not require conscious awareness (Battersby, Golledge \& Marsh, 2006).

In incidental and intentional learning, learning was conceptualized in accordance with the stimuli response principle in the American behavioral psychology in the mid-20th century (Postman \& Keppel, 1969). Incidental learning is different from learning achieved through intentional actions. Intentional learning occurs with the intention of learning a material (or a learning object) and placing it in memory. In the studies conducted in this field, the individuals are said that they will be tested after the assigned tasks. Therefore, individuals behave more carefully while performing their tasks. However, such a situation is not in question in incidental learning. These individuals are not told that they will be tested later, and are expected to achieve the objectives clearly expressed in the tasks, and they are examined whether to focus on the other distracting stimuli or not in the second test, which is conducted without prior notice (Catherine, 2003). 
The appropriateness of the information learned for transferring helps to differentiate between incidental and intentional learning. This situation also reveals the critical importance of teaching (Hulstijn, 2013). Informing the individuals about the test they will undergo later will ensure the control or manipulation of information in the learning experiment.

The concepts of incidental and intentional learning are sometimes confused with implicit and explicit learning concepts and they may even be used interchangeably. There is an important difference between these concepts. For Hulstijn (2013), implicit and explicit learning concepts are related to the location where information is stored in the brain. And the concepts of incidental and intentional learning are related to the way of learning where the information acquired through implicit or explicit ways. In other words, implicit or explicit learning can occur with incidental or intentional learning. As the first stage of this differentiation, the location of storing the information is referred through implicit and explicit learning. While implicit learning takes place in the neocortex part of the brain, explicit learning takes place in other regions such as the hippocampus and temporary lobes where hidden information are located (Hulstijn, 2013). As for the incidental and intentional learning, they are associated with the status of focusing during the learning process. As mentioned earlier, incidental learning is learning a feature of the stimulus while focusing on another feature of the same (Ahmed, 2017). Studies on incidental and intentional learning have generally been conducted on vocabulary and foreign language learning. For example, Hyde and Jenkins (1973) asked the subjects in their study to rate each word in a vocabulary list from the most liked to the least liked meanings (a semantic orientation task), while memorizing some words incidentally (a meaningless orientation task). When the subjects were later assigned a surprise task for remembering the words (i.e., a incidental learning task), it was demonstrated that words in the semantic state were remembered easier than the words recorded incidentally. These and similar studies are thought to give way to incidental learning.

Thanks to the studies conducted on incidental learning, researchers have reached significant findings. In his study where the effect of distracting factors on selective attention was examined, Hagen (1967) expressed that the scores in the educational activities increased when determined by age in primary school years, and the scores in incidental tasks decreased or remained constant. In their study, where Hallahan, Kauffman and Ball (1973) examined the selective attention of sixth grade students by low and high success, compared the incidental learning of students with learning disability and the students without learning disability. In this study, the students in the control group got higher scores from the central tasks, while students with learning disabilities got higher scores from the incidental tasks. However, this difference was not statistically significant.

Pelham and Ross (1977) examined the selective attention of students with reading problems, and compared the scores of students who had reading problems and of those in the control group they got from the central and incidental tasks. At the end of the study, it was observed that the students with reading problems got lower scores in central tasks while they got higher scores in incidental tasks.

In addition to these studies, Parry (1993), Mondria and Boer (1991) revealed in their study, where the effect of contextual richness was examined on the predictability and memorability of words in foreign language learning, that students could learn the meaning of unknown words incidentally in a reading task by learning from the context, however that learning would not be permanent. On the other hand, some researchers stated that incidental or intentional learning could not be superior to each other and that neither incidental learning nor intentional learning was more effective than the other (Nation, 2001; Read, 2004; Laufer \& Hulstijn, 2001; Brown, Waring and Donkaewbua, 2008).

The main research subject of this study is the extent to which incidental learning takes place in mathematics education, whose effect on learning is supported by various studies. In order to research this subject, the following research problem and its sub-problems were formulated. The research problem is "To what extent does incidental learning take place in mathematics education?" and sub-problems are:

- Does incidental learning differ significantly by gender?

- Does the intentional learning differ significantly by gender?

- Does incidental learning differ significantly by the success levels of the students in mathematics?

- Does the intentional learning differ significantly by the success levels of the students in mathematics?

- What kind of a difference is created in success when the incidental factors in questions are increased?

\section{METHODS}

The method of the study was designed as survey, one of the quantitative research designs. As it is known, it is aimed to reveal the current situation as it is, research and explain it in the survey models (Büyüköztürk, Çakmak, Akgün, Karadeniz, Demirel, 2010). Accordingly, our purpose is to reveal the students' current incidental learning status and to interpret the results to be obtained. 


\section{Study Group}

The study group consists of 90 students studying at the 7th grade in 2018-2019 Fall Semester in a public school in Gaziantep province. Students were divided into three groups depending on their success level at mathematics as low, medium and high. While selecting the students by their success level at mathematics, their mathematics teachers were consulted and the exam results of the students were used. As gender was a variable in the research, 45 girls and 45 boys participated in the study group for a balanced distribution among the groups.

\section{Data Collection Tool}

In the study, the success and attention test developed by the researchers was used as data collection tool, which is thought to be a synthesis of the data collection tools used in previous studies on incidental learning and selective attention. The developed data collection tool consists of two consecutive tests with central and incidental tasks. The test with central tasks, consists of four operation questions, determination of expressions which involve rational numbers and a mathematical problem. After the questions in the data collection tool were developed, they were submitted to expert opinion for validation of questions, and the validity - reliability analyses were conducted using item - test analysis software after the application.

- Arithmetical Operations: In this task, students are given a table with 7 provinces in Turkey and the plate numbers of the provinces. The central task is to cover the operations with the plate numbers of the provinces. The incidental task is the extent of remembering the plate number of the provinces. There are 6 central and 7 incidental tasks in the question group.

- Determination of Expressions Indicating a Rational Number: In this task, students are given 6 geometric shapes and written expressions within these geometric shapes. The central task is to determine which of these statements include rational numbers, and the incidental task is a match for remembering which expression is in which geometric shape. There are 6 central and 6 incidental tasks in this questions group.

- Mathematical Problem: In this task, students are presented with a problem situation involving special days and their dates (for example, December 3, International Day of Persons with Disabilities). The central task is to calculate the exam score of students who give right and wrong answers to the situations here, and the incidental task is to make a match between the dates and the special days. The questions in this group include 1 central and 5 incidental tasks.

Within the scope of the main articles above, a total of 31 items were addressed to the students, 13 of which were central tasks and 18 were incidental tasks.

\section{Data Analysis}

For the analysis of the data, normality tests were initially applied followed by ANOVA, Mann Whitney U, Kruskal Wallis $\mathrm{H}$ and Wilcoxon Signed Ranks tests, which were used to determine the significant differences between the groups in addition to the descriptive statistics.

\section{FINDINGS}

In this part of the study, findings regarding the research problems will be presented. Findings will be provided in the same order of sub-problems in the study.

\section{Findings regarding the validity and reliability of the problems}

After coding the answers of the students for the questions consisting of 13 central and 18 incidental tasks as right - wrong ( 1 - 0 ) in the data collection tool and analyzing them in TAP (Test Analysis Program), the average difficulty of items was found to be 0.55 and the average discrimination power was found to be 0.44. In addition, the calculated Cronbach alpha internal consistency coefficient of the test was 0.73 .

\section{Findings regarding the examination of incidental learning scores by gender}

In order to determine whether incidental learning scores differ significantly by gender, the normality of the data was examined first. In Table 1, the results of the Kolmogorov-Smirnov Test are provided regarding the normality of the data. 
Table 1. Normality test results of incidental learning success scores

\begin{tabular}{lccccccc}
\hline & \multicolumn{3}{c}{ Kolmogorov-Smirnov $^{\mathrm{a}}$} & \multicolumn{3}{c}{ Shapiro-Wilk } \\
\cline { 2 - 7 } Incidental L.S.P & Stat & $\mathrm{sd}$ & $\mathrm{p}$ & Statistic & $\mathrm{sd}$ & $\mathrm{p}$ \\
& .076 & 86 & $.200^{*}$ & .986 & 86 & .467 \\
\hline
\end{tabular}

As seen in Table 1, Kolmogorov-Smirnov test results show $(0.200>0.05)$ that the data is distributed normally. For this reason, independent sample T-test results can be checked for the difference between incidental learning success scores by gender (Table 2 and 3 ).

Table 2. Group Statistics for incidental learning success scores

\begin{tabular}{lccccc}
\hline & Gender & $\mathrm{N}$ & Mean & Standart Dev. & Mean of Standart Error \\
\cline { 2 - 6 } Incidental & Female & 43 & 48.5271 & 18.71963 & 2.85472 \\
L.S.P & Male & 43 & 46.0465 & 14.40634 & 2.19695 \\
\hline
\end{tabular}

According to Table 2, while the average of female students' incidental learning success scores (incidental LSP) is 48.5271, the average of incidental learning success scores of male students is 46.0465. Although the averages are close to each other, the averages of female students are higher. The t-test result regarding the significance of this difference is presented in Table 3.

Table 3. Difference between incidental learning success scores by gender

\begin{tabular}{|c|c|c|c|c|c|c|c|c|}
\hline \multirow{3}{*}{ Incidental } & \multirow[b]{2}{*}{ Groups } & \multirow[b]{2}{*}{$\mathrm{N}$} & \multirow[b]{2}{*}{ Mean } & \multirow[b]{2}{*}{ SS } & \multirow[b]{2}{*}{$\mathrm{Sh}_{\mathrm{g}}$} & \multicolumn{3}{|c|}{ T test } \\
\hline & & & & & & $\mathrm{t}$ & $\mathrm{Sd}$ & $\mathrm{p}$ \\
\hline & Female & 43 & 48.5271 & 18.71963 & 8.85472 & 60 & & \\
\hline L.S.P & Male & 43 & 46.0465 & 14.40634 & 2.19695 & & 04 & .490 \\
\hline
\end{tabular}

As seen in Table 3, the p value is > .05 (.493), hence, there is no significant difference between incidental learning success scores by gender.

\section{Findings regarding the examination of intentional learning scores by gender}

The normality test of the intentional learning scores is presented in Table $\mathbf{4}$, while the findings regarding the group statistics are given in Table $\mathbf{5}$.

Table 4. Normality test results for intentional learning scores

\begin{tabular}{ccccccc}
\hline & \multicolumn{3}{c}{ Kolmogorov-Smirnova $^{\mathrm{a}}$} & \multicolumn{3}{c}{ Shapiro-Wilk } \\
\cline { 2 - 7 } Intentional L.S.P & Statistic & $\mathrm{sd}$ & $\mathrm{p}$ & Statistic & $\mathrm{sd}$ & $\mathrm{p}$ \\
& .165 & 86 & .000 & .969 & 86 & .034 \\
\hline
\end{tabular}

In Table 4, it is seen that $\mathrm{p}$ value is lower than .05 , hence, the data is not normally distributed. The group statistics by gender are as follows:

Table 5. Group statistics for intentional learning success scores

\begin{tabular}{lccc}
\hline Gender & Mean & N & Standart Deviation \\
\hline Female & 59.2129 & 43 & 22.30295 \\
Male & 54.3828 & 43 & 15.69246 \\
Total & 56.7979 & 86 & 19.32263 \\
\hline
\end{tabular}

In Table 5, the average of the central score of female students (59.2129) is higher than the average of the central score of male students (54.3828). Statistical results indicating the significance of this difference 
are presented in Table 6. As the data was not normally distributed, Mann Whitney U test was used instead of Independent Sample T-test.

Table 6. Difference between intentional learning success scores by gender

\begin{tabular}{lc}
\hline & Intentional Learning Success scores \\
\hline Mann-Whitney U & 808.500 \\
Wilcoxon W & 1754.500 \\
$\mathrm{Z}$ & -1.013 \\
$\mathrm{p}$ & .311 \\
\hline
\end{tabular}

Groups Variable: Gender

According to Table 6 , since the $\mathrm{p}$ value is $>.05$ (.311), there is no significant difference between the intentional learning scores by gender.

\section{Investigation of incidental learning scores by students' success in mathematics lessons}

Statistical analyses were conducted and examined to see whether incidental learning scores differed significantly by the success level of students in mathematics. Levene Test results for the homogeneity of group variances are presented in Table 7.

Table 7. Levene test results for the equality of group variances

\begin{tabular}{cccc}
\hline Levene statistic & sd1 & Sd 2 & p. \\
.055 & 2 & 83 & .947 \\
\hline
\end{tabular}

In Table 7, as the p value is greater than .05 (.947), variances are considered to be homogeneous. The ANOVA result for the relationship between incidental learning scores by the success level of students at mathematics is provided in Table 8.

Table 8. Incidental Learning Scores by the Success Level of Students at Mathematics

\begin{tabular}{lccccc}
\hline & Sum of Squares & sd & Mean Square & F & p \\
\cline { 2 - 6 } Between Groups & 4327.905 & 2 & 2163.952 & 9.336 & .000 \\
Within Groups & 19239.020 & 83 & 231.795 & & \\
Total & 23566.925 & 85 & & & \\
\hline
\end{tabular}

According to Table 8, there is a significant difference between the students' success levels (low - medium high) and incidental learning scores. The results of the Tukey Test, used for multiple comparisons regarding these differences, are provided in Table 9.

Table 9. Multiple comparison of success level at mathematics and incidental learning scores

\begin{tabular}{lccccccc}
\hline & Success & Success & Mean Difference & \multicolumn{3}{c}{$95 \%$ Confidence Interval } \\
& Level-1 & Level-2 & $(1-2)$ & Std. Error & $\mathrm{p}$ & Low & High \\
\cline { 2 - 7 } & Low & High & $20.45699^{*}$ & 5.17625 & $.000^{*}$ & 8.1040 & 32.8100 \\
& & Medium & 9.01163 & 4.97060 & .172 & -2.8506 & 20.8738 \\
\cline { 2 - 8 } Tukey & High & Low & $-20.45699^{*}$ & 5.17625 & $.000^{*}$ & -32.8100 & -8.1040 \\
& & Medium & $-11.44536^{*}$ & 3.58718 & $.006^{*}$ & -20.0061 & -2.8846 \\
\cline { 2 - 8 } & \multirow{2}{*}{ Medium } & Low & -9.01163 & 4.97060 & .172 & -20.8738 & 2.8506 \\
& & High & $11.44536^{*}$ & 3.58718 & $.006^{*}$ & 2.8846 & 20.0061 \\
\hline
\end{tabular}

According to Table 9, there is a significant difference between incidental learning scores of students with low and high success levels at mathematics $(\mathrm{p}<.05)$. When the table is taken into consideration, students with low success level have higher incidental learning scores compared to the students with high success level and this difference is significant. It is seen that the students with medium success level only showed a significant difference compared to the students with high success level. There is no significant difference between the average score of students with low success and the average success score of students with medium success. 


\section{Investigation of intentional learning scores by students' success level at mathematics}

The results of the Kruskal Wallis H Test are as follows, which was performed on the data to indicate the significance of learning score differences of students depending on their success levels in mathematics (Table 10):

Table 10. Intentional learning scores by the students' success level at mathematics

\begin{tabular}{lc}
\hline & Intentional learning score \\
Ki-square & 40,460 \\
$\mathrm{sd}$ & 2 \\
$\mathrm{p}$ &, 000 \\
\hline
\end{tabular}

a. Kruskal Wallis Test

b. Grouping Variable: Success level

According to Table 10, there was a significant difference between the students' intentional scores by their success levels $(\mathrm{p}<.05)$. As expected, the students with low success at mathematics got lower scores in a normal success test compared to the students with higher success at mathematics.

\section{Relationship between incidental learning scores - intentional learning scores and success in mathematics lesson}

The distribution diagram of central and incidental scores of the students basing on their success is presented in Figure 1.

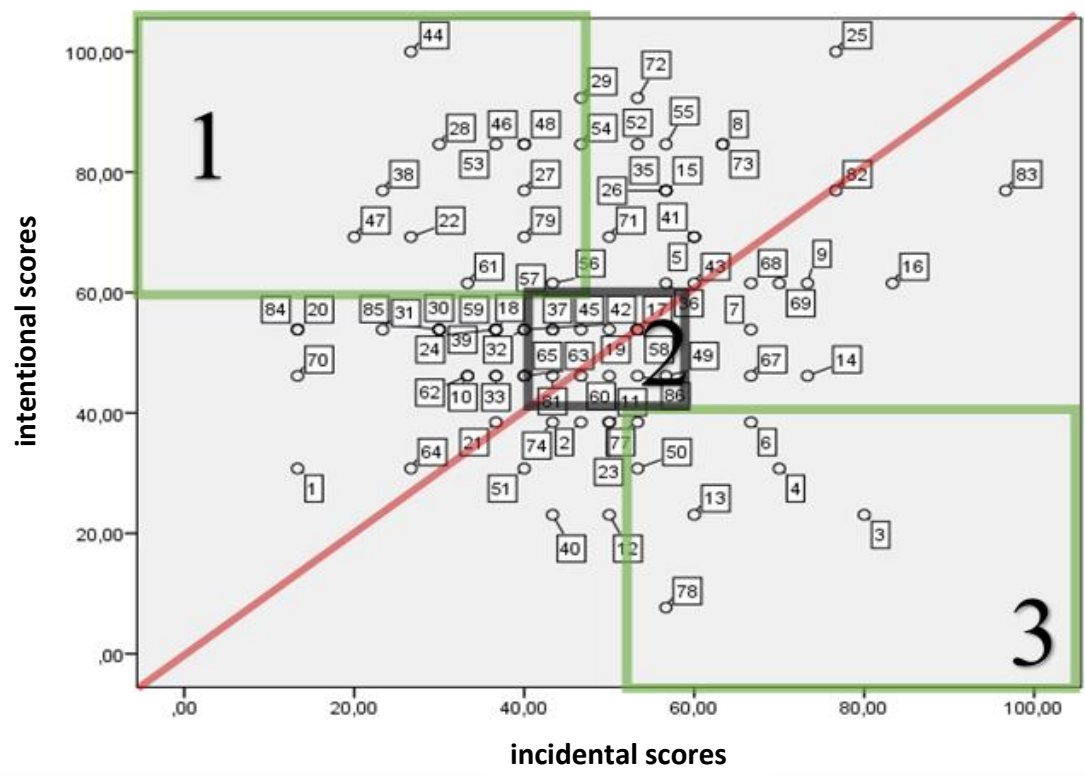

FIGURE 1. Scatter diagram of incidental learning - central (intentional) learning and success level

According to Figure 1, students with high success are in the 1st cell while the students with low success are in the 3 rd cell. As for the students with medium success, they are in the 2 nd cell. This situation shows that the intentional scores of students with low success are low while the incidental scores are high; and the intentional scores of students with high success are high but their incidental scores are low.

\section{Findings regarding the increasing incidental factors in questions}

In the three questions in the data collection tool, there are 7 incidental tasks in the first group (T_1), 6 in the second group (T_2) and 5 in the third group (T_3). Wilcoxon Test, which is the nonparametric equivalent of the One Sample T Test, was applied to the data in order to determine the efficiency of 
incidental tasks was in answering these questions basing on the success of the students. The comparison between the questions in the low success group is given in Table 11.

Table 11. Incidental learning scores comparison in low group

\begin{tabular}{|c|c|c|c|c|c|c|}
\hline & & $\mathrm{N}$ & Mean Rank & $\begin{array}{l}\text { Sum of } \\
\text { Ranks }\end{array}$ & $\mathrm{Z}$ & $\begin{array}{l}\text { Asymp. Sig. (2- } \\
\text { tailed) }\end{array}$ \\
\hline \multirow[t]{4}{*}{ T_3 - T_1 } & Negative Ranks & $26^{a}$ & 17,00 & 442,00 & $-4,330^{a}$ & 000 \\
\hline & Positive Ranks & $4^{\mathrm{b}}$ & 5,75 & 23,00 & & \\
\hline & Ties & $0^{c}$ & & & & \\
\hline & Total & 30 & & & & \\
\hline \multirow[t]{4}{*}{ T_3 - T_2 } & Negative Ranks & $18^{\mathrm{a}}$ & 11,75 & 211,50 & $-3,414^{a}$ & ,001 \\
\hline & Positive Ranks & $3^{\mathrm{b}}$ & 6,50 & 19,50 & & \\
\hline & Ties & $9^{c}$ & & & & \\
\hline & Total & 30 & & & & \\
\hline \multirow[t]{4}{*}{$\mathrm{T} \_2-\mathrm{T} \_1$} & Negative Ranks & $20^{\mathrm{a}}$ & 15,62 & 312,50 & $-2,992^{a}$ & 003 \\
\hline & Positive Ranks & $7^{\mathrm{b}}$ & 9,36 & 65,50 & & \\
\hline & Ties & $3^{c}$ & & & & \\
\hline & Total & 30 & & & & \\
\hline
\end{tabular}

As can be seen in Table 11, students have reached the highest correct response rate in T_1, which is the highest number of incidental tasks. T_2 and T_3 follow this group, respectively. A similar comparisons is provided Table 12 for students with medium success.

Table 12. Incidental learning scores comparison in medium group

\begin{tabular}{|c|c|c|c|c|c|c|}
\hline & & $\mathrm{N}$ & Mean Rank & $\begin{array}{l}\text { Sum of } \\
\text { Ranks }\end{array}$ & $\mathrm{Z}$ & $\begin{array}{l}\text { Asymp. Sig. (2- } \\
\text { tailed) }\end{array}$ \\
\hline \multirow[t]{4}{*}{ T_3 - T_1 } & Negative Ranks & $26^{a}$ & 14,31 & 372,00 & $-4,440^{a}$ & ,000 \\
\hline & Positive Ranks & $1^{\mathrm{b}}$ & 6,00 & 6,00 & & \\
\hline & Ties & $3^{c}$ & & & & \\
\hline & Total & 30 & & & & \\
\hline \multirow[t]{4}{*}{ T_3 - T_2 } & Negative Ranks & $19^{a}$ & 11,42 & 217,00 & $-2,442^{a}$ & ,015 \\
\hline & Positive Ranks & $4^{\mathrm{b}}$ & 14,75 & 59,00 & & \\
\hline & Ties & $7^{c}$ & & & & \\
\hline & Total & 30 & & & & \\
\hline \multirow[t]{4}{*}{ T_2 - T_1 } & Negative Ranks & $19^{a}$ & 12,53 & 238,00 & $-3,072^{a}$ & ,002 \\
\hline & Positive Ranks & $4^{\mathrm{b}}$ & 9,50 & 38,00 & & \\
\hline & Ties & $7 \mathrm{c}$ & & & & \\
\hline & Total & 30 & & & & \\
\hline
\end{tabular}

As can be seen in Table 12, students with medium success levels are seen to be more successful in these tasks as the number of incidental tasks increases. Finally, the status of students with high success levels to complete these tasks by incidental number of tasks is given in Table 13. 
Table 13. Incidental learning scores comparison in high group

\begin{tabular}{|c|c|c|c|c|c|c|}
\hline & & $\mathrm{N}$ & Mean Rank & $\begin{array}{l}\text { Sum of } \\
\text { Ranks }\end{array}$ & $\mathrm{Z}$ & $\begin{array}{l}\text { Asymp. Sig. (2- } \\
\text { tailed) }\end{array}$ \\
\hline \multirow[t]{4}{*}{$\mathrm{T} \_3-\mathrm{T} \_1$} & Negative Ranks & $26^{a}$ & 14,33 & 372,50 & $-4,446^{a}$ & ,000 \\
\hline & Positive Ranks & $1^{b}$ & 5,50 & 5,50 & & \\
\hline & Ties & $3^{c}$ & & & & \\
\hline & Total & 30 & & & & \\
\hline \multirow[t]{4}{*}{ T_3 - T_2 } & Negative Ranks & $21^{\mathrm{a}}$ & 13,98 & 293,00 & $-3,050^{a}$ & ,002 \\
\hline & Positive Ranks & $5^{b}$ & 11,50 & 57,50 & & \\
\hline & Ties & $4 c$ & & & & \\
\hline & Total & 30 & & & & \\
\hline \multirow[t]{4}{*}{ T_2 - T_1 } & Negative Ranks & $18^{\mathrm{a}}$ & 12,69 & 228,50 & $-2,262^{\mathrm{a}}$ & ,024 \\
\hline & Positive Ranks & $6^{\mathrm{b}}$ & 11,92 & 71,50 & & \\
\hline & Ties & $6^{c}$ & & & & \\
\hline & Total & 30 & & & & \\
\hline
\end{tabular}

According to the findings obtained in Table 13, it is seen that as the number of incidental tasks increases, the rate of performing these tasks also increase in the other two groups.

\section{DISCUSSION and CONCLUSIONS}

The aim of this study was to determine the students' incidental learning depending on their academic success level. For this purpose, the different results obtained from the questions involving central and incidental tasks developed in order to reveal the incidental learning in students with different success levels were examined. In compliance with the purpose of the study, the central and incidental task scores were compared between students with low and high success at mathematics. Findings show that students with high success are relatively more successful in central tasks. When we look at the incidental scores of students with high success, there is a statistically significant decrease. This suggests that the students with high success consider the central tasks only as a question or problem that needs to be solved. The relatively significant difference between the averages of central and incidental scores of students with high success supports this idea.

The averages between central and incidental scores were close among the students with low success levels. This indicates that students with low success levels perform incidental learning better. Similar findings are also seen in the study of Pelham and Ross (1977). Pelham and Ross (1977) stated that students having reading problems scored low in central tasks compared to normal students and got higher scores from incidental tasks. In addition to these, the same situation was observed in the study conducted by Hallahan, Kauffman and Ball (1973), which compared the incidental learning scores of students with learning disabilities and the students without learning disabilities. In this study, the students in the control group got higher scores from the central tasks, while students with learning disabilities got higher scores from the incidental tasks. Although the findings of this study conducted on a reading text were not statistically significant, the findings obtained in this study provided statistically significant results.

Situations similar to the assumptions of the Schouten-Van Parraren theory in the relevant literature were also seen in this study. This theory regards incidental learning on vocabulary in a foreign language. According to the theory, the words learned from a certain list may not be known outside the list, and the words learned from the list may not be memorable as they are removed from the context (Mondria, Boer, 1991). In this study, it was observed that the students with high success levels used the plate number of the provinces listed in the central tasks only to use in the operations and did not keep them in mind because they were far from the context. Students with low success at mathematics kept this information in mind relatively better as they focused their attention on the plate numbers of the provinces and not on mathematical operations. Besides, according to Schounten-Van Parraren theory, the more challenging the context is, the easier it is to guess the words. Since the purpose of the study is to predict and reveal incidental information obtained from central tasks instead of word predictions, the relatively more occurrence of incidental learning is similar to the situation mentioned in theory as the operations are more challenging for students with low success level at mathematics.

Finally, in the research performed to see how the number incidental factors in a mathematical activity affected the scores obtained from the relevant question, the obtained findings indicate were 
obtained that the rate of answering incidental tasks would increase as the incidental factors increase. The findings are also seen in the study conducted by Prawat (1989). Prawat, states that when distracting factors increase in a mathematical problem, students with low success focus their attention on these factors. Accordingly, the increase of incidental factors (distracting factors) in a question makes it easier to remember this information. More clearly, the increase of distracting factors in the question strengthens incidental learning. This situation also emerged in the study of Jitendra and Kameeuni (1996). In this study, it was observed that students with low success were focusing more on the irrelevant, distracting and unnecessary details in the question. Depending on the findings obtained as a result of the study, the following suggestions can be made for the field of mathematics education.

- The understanding that only students with high success learn something in mathematics lessons and activities, and other students do not learn something should be changed.

- Students with low success pay more attention to other factors in question than students with high success. This situation should not be ignored in textbook writing and in-class activities.

- It should not be forgotten that too many distracting factors will create cognitive load in questions and activities.

- The concept of attention should be taken into consideration by those directly or indirectly involved in education.

\section{REFERENCES}

Ahmed, S. (2017). Intentional learning vs incidental learning. J. Psychol. Clin. Psychiatry, 7(00426), 1015406.

Battersby, S. E., Golledge, R. G., \& Marsh, M. J. (2006). Incidental learning of geospatial concepts across grade levels: Map overlay. Journal of Geography, 105(4), 139-146.

Brown, R., Waring, R., \& Donkaewbua, S. (2008). Incidental vocabulary acquisition from reading, readingwhile-listening, and listening to stories. Reading in a Foreign Language, 20, 136-63.

Büyüköztürk, Ş., Çakmak, E., Akgün, Ö., Karadeniz, Ş. \& Demirel, F. (2010). Bilimsel araştırma yöntemleri. Ankara: Pegem Publishing.

Catherine, J.D. (2003). The handbook of second language Acquisition. UK: Blackwell Publishing Ltd.

Craik, F. I., \& Lockhart, R. S. (1972). Levels of processing: A framework for memory research. Journal of verbal learning and verbal behavior, 11(6), 671-684.

Hagen, J. W. (1967). The effect of distraction on selective attention. Child development, 38 (3), 685-694.

Hallahan, D. P., Kauffman, J. M., \& Ball, D. W. (1973). Selective attention and cognitive tempo of low achieving and high achieving sixth grade males. Perceptual and Motor Skills, 36(2), 579-583.

Hulstijn, J. H. (2013). Incidental learning in second language acquisition. In C. A. Chapelle (Ed.), The encyclopedia of applied linguistics (Vol. 5, pp. 2632-2640). Wiley-Blackwell.

Hyde, T. S., \& Jenkins, J. J. (1973). Recall for words as a function of semantic, graphic, and syntactic orienting tasks. Journal of Verbal Learning and Verbal Behavior, 12, 471-80.

Jitendra, A. K., \& Kameenui, E. J. (1996). Experts' and novices' error patterns in solving part-whole mathematical word problems. The Journal of Educational Research, 90(1), 42-51.

Laufer, B., \& Hulstijn, J. (2001). Incidental vocabulary acquisition in a second language: The construct of task-induced involvement. Applied Linguistics, 22, 1-26.

Marsick, V., \& Watkins, K. (2015). Informal and Incidental Learning in the Workplace (Routledge Revivals). London: Routledge.

Mondria, J. A., \& Boer, M. W. D. (1991). The effects of contextual richness on the guess ability and the retention of words in a foreign Language1. Applied linguistics, 12(3), 249-267.

Nation, P. (2001). Learning vocabulary in another language. England: Cambridge University Press.

Parry, K. (1993). Too many words: Learning the vocabulary of an academic subject. Second language reading and vocabulary learning, 109-129.

Pelham, W. E., \& Ross, A. O. (1977). Selective attention in children with reading problems: A developmental study of incidental learning. Journal of Abnormal Child Psychology, 5(1), 1-8.

Postman, L., \& Keppel, G. (Eds.). (1969). Verbal learning and memory. Harmondsworth, England: Penguin Books.

Prawat, R. S. (1989). Promoting access to knowledge, strategy, and disposition in students: A research synthesis. Review of educational research, 59(1), 1-41.

Read, J. (2004). Research in teaching vocabulary. Annual Review of Applied Linguistics, 24, 146-61.

Smith, E.E. \& Kosslyn, S.M. (2017). Bilişsel Psikoloji- Zihin ve Beyin (Çev. M. Şahin). Ankara: Nobel Akademik Yayıncllı. 